\title{
Potentiodynamic Study of Glucose Electro-Oxidation at Bright Platinum Electrodes
}

\author{
M. F. L. de Mele, H. A. Videla, and A. J. Arvía* \\ Instituto de Investigaciones Fisicoquimicas Teóricas y Aplicadas (INIFTA), Casilla de Correo 16, Sucursal4,1900 La Plata, \\ Argentina
}

\begin{abstract}
The potentiodynamic electro-oxidation of glucose on bright $\mathrm{Pt}$ in different electrolytes has been investigated through the application of combined potential/time perturbation programs. The $E / I$ response in the $0.6-1.0 \mathrm{~V}$ range $(v s$. SCE) depends on the perturbation conditions, the electrolyte composition, and the presence of $\mathrm{CO}_{2}$. The glucose electroadsorption process has been measured through potentiostatic current transients. The influence of anions in the electro-oxidation reaction has also been studied. The interaction between electroadsorbed species and H-adatoms, as well as the overall response of the electrochemical system suggests a reaction pattern that is more complex than those previously reported.
\end{abstract}

Since the end of the 1960's several research works dealing with the electro-oxidation of glucose have been made (1-3). They were mainly focused in the development of fuel cells as power sources for cardiac pacemakers $(4)$ or glucose sensors $(5,6)$. The reaction was studied with different perturbation techniques on either smooth $(7,8)$ or platınized platinum $(9-12)$ electrodes in neutral (1-14) or acid solutions (15). The reaction at $p H \quad 7.5$ was investigated by using mass spectrometry techniques and $p \mathrm{H}$ measurements to identify the reaction products, which are found in the $-0.55-0.45 \mathrm{~V}$ (SCE) potential range. The only reaction product found was glucono- $\delta$-lactone. However, recent results (10) indicate that in the $-0.2-0.2 \mathrm{~V}$ (SCE) potential range the reaction continues beyond the formation of gluconic acid, considering that the number of charges transferred per molecule is larger than 4.

On the basis that gluconic acid is the main product of the reaction, different mechanisms $(7,8,13,15)$ have been proposed depending on the characteristics of the electrocatalytic surface in the different potential regions. In the potential region corresponding to the hydrogen adatom formation, one of the mechanisms proposed considers the reactivity of the hemiacetalic group of the glucose molecule with platinum and adsorbed hydrogen yielding glucono- $\delta$-lactone, the latter undergoes a hydrolysis reaction to produce gluconic acid $(7,8)$. On the other hand, reduced $\mathrm{CO}_{2}$ or a similar product originated by a destructive adsorption was also posiulated in the same potential range $(2,14)$. At the end of the double layer region the oxidation reaction was explained through the heterogeneous splitting of the $\mathrm{C}_{1}-\mathrm{H}$ bond of glucose (8).

Despite the various proposed mechanisms, which were derived from kinetic data obtained within a rather limited range of experimental conditions, information is still scarce about the influence of the solution composition, ionic strength, and buffer capacity on the rate of the reaction. This work pays special attention to the influence of the solution composition on the electro-oxidation of glucose through changes that are produced in the corresponding potentiodynamic $E / I$ profiles and it attempts to interpret the electro-oxidation of glucose on platinum through a complex reaction pattern that could be applied to biological as well as nonbiological systems.

\section{Experimental}

Experiments were carried out in a three-compartment Pyrex glass cell. A smooth platinum wire (polycrystalline, specpure, Johnson, Matthey Chemical) of 0.16 $\mathrm{cm}^{2}$ apparent area was used. The counterelectrode was also made of platinum. A properly shielded saturated calomel electrode was used as reference. The working

* Electrochemical Society Active Member.

Key words: anodic oxidation, glucose, platinum, lineal potential sweeps. electrode was perturbated with different potential/ time programs, including repetitive triangular sweeps and combined potential/time perturbation functions using a fast risetime potentiostat operated with a multiple signal generator (Fig. 1). Each successive potential step has a particular function (Fig. 1a). The electroadsorbed species is electro-oxidized at $E_{1}$ and simultaneously an oxygen-containing film is formed on the electrode. Any molecular oxygen produced at $E_{1}$ is removed at the potential $E_{2}$. Then, at $E_{\text {ad }}$ the adsorption of glucose takes place. Usually the electrode is first activated by applying two potential steps at $E_{1}=1.8 \mathrm{~V}$ $\left(t_{1}=10 \mathrm{sec}\right)$ and at $E_{2}=0.8 \mathrm{~V}\left(t_{2}=180 \mathrm{sec}\right)$. Later, the electrode is stepped to $E_{\text {ad }}$ for the time $t_{\text {ad }}$ and immediately afterwards the first potential triangular potential sweep (TPS) is run at $v=0.1 \mathrm{~V} / \mathrm{sec}$. The current transient during the potential holding at $E_{a d}$ is also recorded. Occasionally the potential perturbation program depicted in Fig. 1b was also employed.

The compositions of the electrolyte solutions are given in Table I, where $c$ stands for the molar concentration of the organic substance, $I$ is the ionic strength, and $\beta$ is the buffer capacity of the electrolyte mixture. Solutions were prepared from triply distilled water and $A R$ chemicals. Runs were made at $30^{\circ} \mathrm{C}$. Occasionally, experiments were also made in the $30^{\circ}-$ $64^{\circ} \mathrm{C}$ temperature range.

\section{Results}

The potentiodynamic $E / I$ display run at $0.1 \mathrm{~V} / \mathrm{sec}$ between $E_{3}=-0.6 \mathrm{~V}$ and $E_{4}=0.8 \mathrm{~V}$ in the positive potential direction with solution 1 (Fig. 2) shows three anodic current peaks (I, II, III) related to the presence of glucose in good agreement with previous results. Likewise, the reverse potential scan exhibits a net anodic current peak (V) preceded by a wide hump (IV) located at the positive potential side of peak $V$. In the presence of glucose the regions of the voltammograms related to the electroadsorption/electrodesorption of hydrogen and oxygen adatoms are modified, the more drastic changes being associated with the former

Table I. Characteristics of the electrolyte solution

\begin{tabular}{|c|c|c|c|c|c|c|}
\hline $\begin{array}{l}\text { Solu- } \\
\text { tion } \\
N^{\circ}\end{array}$ & $c / M$ & $\begin{array}{c}I / M \\
\mathrm{~K}_{2} \mathrm{HPO}_{4-}^{-} \\
\mathrm{KH}_{2} \mathrm{HPO}_{4}\end{array}$ & $\beta$ & $p H$ & $\begin{array}{c}I / M \\
\mathrm{KaSO}_{4}\end{array}$ & $\begin{array}{c}I / M \\
\text { Total }\end{array}$ \\
\hline $\begin{array}{r}1 \\
2 \\
3 \\
4 \\
5 \\
6 \\
7 \\
8 \\
9 \\
10 \\
11 \\
12\end{array}$ & $\begin{array}{l}0.10 \\
0.10 \\
0.10 \\
0.10 \\
0.10 \\
0.03 \\
0.10 \\
0.10 \\
0.03 \\
0.03 \\
0.10 \\
0.10\end{array}$ & $\begin{array}{l}0.20 \\
0.05 \\
0.20 \\
0.20 \\
0.05 \\
0 \\
0 \\
0 \\
0.20 \\
0.05 \\
0.40 \\
0.04\end{array}$ & $\begin{array}{l}9.5 \\
2.7 \\
9.5 \\
9.5 \\
2.7 \\
- \\
- \\
\overline{5.4} \\
1.8 \\
\overrightarrow{2.8}\end{array}$ & $\begin{array}{l}7.0 \\
7.0 \\
6.1 \\
7.0 \\
7.0 \\
9.5 \\
7.0 \\
2.6 \\
7.4 \\
7.4 \\
7.0 \\
7.1\end{array}$ & $\begin{array}{l}0.80 \\
0.95 \\
0.80 \\
0 \\
0 \\
0.30 \\
0.30 \\
0.30 \\
0.80 \\
0.95 \\
0 \\
0\end{array}$ & $\begin{array}{l}1.00 \\
1.00 \\
1.00 \\
0.20 \\
0.05 \\
0.30 \\
0.30 \\
0.30 \\
1.00 \\
1.00 \\
0.40 \\
0.04\end{array}$ \\
\hline
\end{tabular}




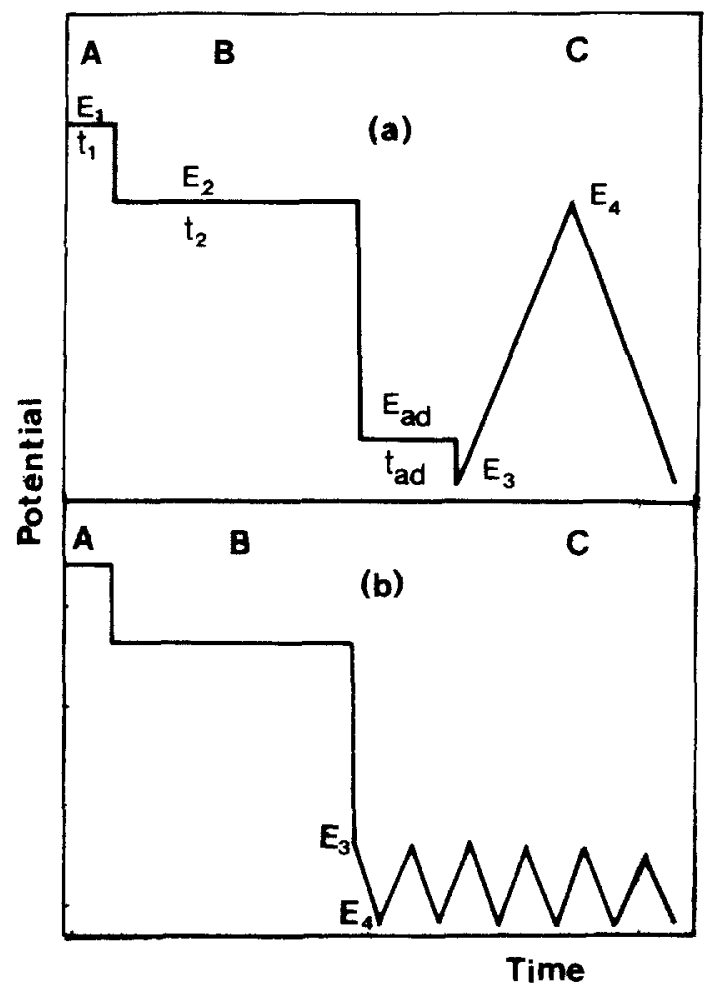

Fig. 1. Potential/time perturbotion programs. $A=10 \mathrm{sec}, B=$ $180 \mathrm{sec}, \mathrm{C}=$ triangular potential sweep (TPS).

processes. Peak $I$ is found in the potential range of the electroadsorption of hydrogen adatoms. The potential of peak II is closely located in the region where the $\mathrm{Pt}(\mathrm{OH})_{\text {ad }}$ species are formed. Peak III is recorded in the potential range where the platinum surface is practically completely covered with a monolayer of oxygen-containing species, probably $\mathrm{PtO}_{\mathrm{ad}}$. On the other hand, peaks IV and V only occur after a partial electrodesorption of the oxygen-containing species covering the platinum surface.

At the maximum adsorption potential $\left(E_{\mathrm{ad}}=-0.4\right)$ (7) the largest contribution of peak I is obtained when $t_{\mathrm{ad}}$ is about $1 \mathrm{sec}$. The increase of $t_{\mathrm{ad}}$ produces a gradual inhibition of peak I, so that in the case of solution 1 for $t_{\mathrm{ad}}=10 \mathrm{sec}$ the current recorded in the potential range of current peak I becomes smaller than that corresponding to the blank (Fig. 2). This inhibition, which can, in principle, be attributed to some product formed in the initial electroadsorption reaction, is more remarkable as the temperature is increased.

The current transients recorded at $E_{\text {ad }}$ after prepolarizing the electrode show an initial abrupt current increase followed by a rapid decay approaching zero (Fig. 3 and 4). The transient currents obtained

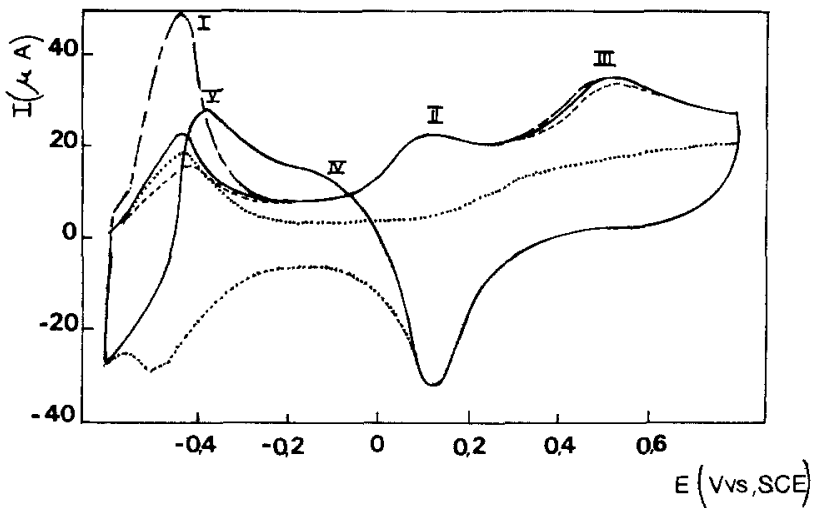

Fig. 2. Potentiodynamic $E / I$ profiles run in solution $11(0.1 \mathrm{M}$ glucose). $E_{\mathrm{ad}}=-0.4 \mathrm{~V}, \mathrm{t}_{\mathrm{ad}}=(---) 1 \mathrm{sec},(\longrightarrow) 5 \mathrm{sec}$, $(--) 10 \mathrm{sec},(\cdots)$ base electrolyte; $r=30^{\circ} \mathrm{C}$

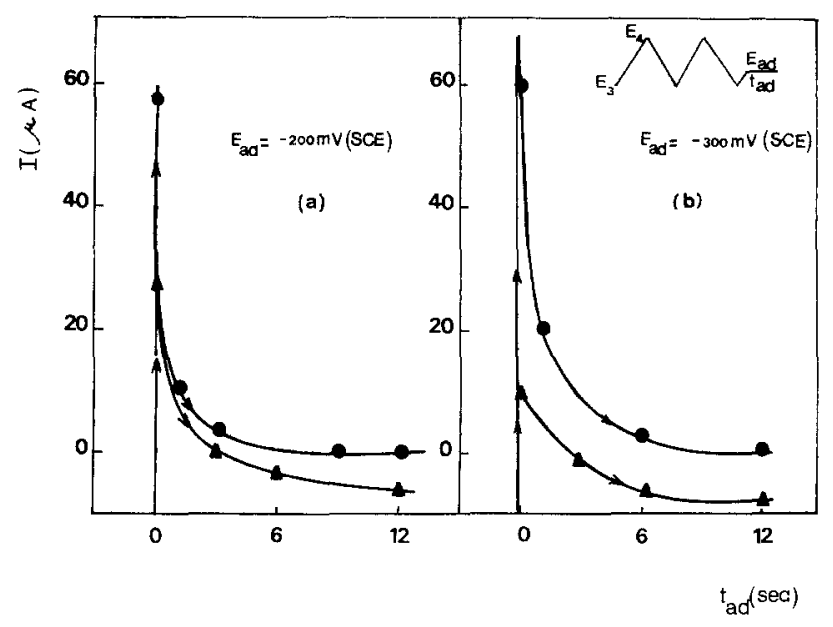

Fig. 3. (a) Current transient recorded ot $E_{\mathrm{ad}}=-0.2 \mathrm{~V}\left(30^{\circ} \mathrm{C}\right)$; solution $11(0.1 \mathrm{M}$ glucose) $(-\rightarrow$ solution 12 (0.1M glucose) $(-A-)$. (b) Current transient recorded ot $E_{\mathrm{ad}}=-0.3 \mathrm{~V}\left(30^{\circ} \mathrm{C}\right)$; solution $11(0.1 \mathrm{M}$ glucose) (-$(-\mathbf{A}-)$

with solution 11 are higher than those resulting from solution 12 (Fig. 3). With solutions containing gluconic acid the charge involved in the current transient is much smaller than that recorded with the solutions containing glucose (Fig. 4).

The single TPS $E / I$ profiles run with solution 9 with $E_{\text {ad }}=-0.4 \mathrm{~V}$ (Fig. 5), show the following features as $t_{\mathrm{ad}}$ increases from $1 \mathrm{~min}$ to $60 \mathrm{~min}$ : (i) a strong inhibition for the electroadsorption and electrodesorption of hydrogen adatoms; (ii) a net decrease of the current peaks II and III and the shift of the corresponding peak potentials toward the positive potential side; (iii) a definite decrease of the anodic current contribution during the negative potential going scan; and (iv) no appreciable change in the oxygen-electrodesorption charge. The activation of the electrode, however, can be recovered after anodizing during a certain time at a potential greater than $0.8 \mathrm{~V}$ but during the second TPS, when $E_{4}$ is lower than the potential of current peak II, the inhibition of current peak I appears again. This effect is observed for all the elec-

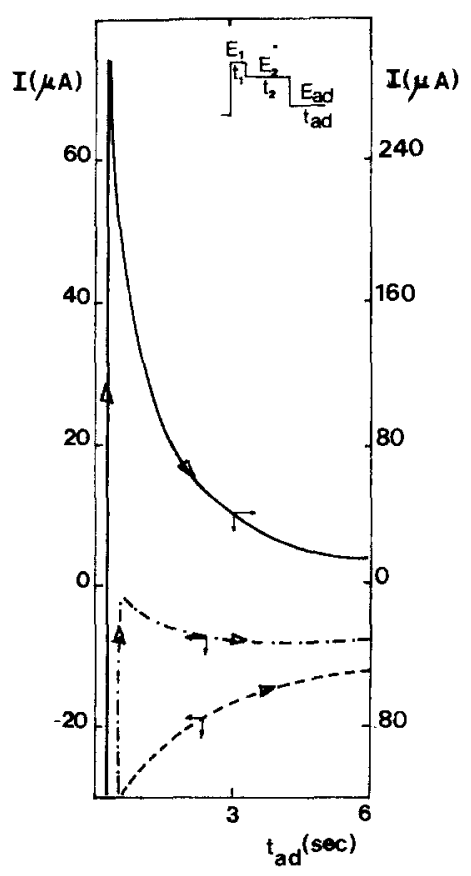

Fig. 4. Current transient recorded at $E_{\mathrm{ad}}=-0.4 \mathrm{~V}\left(37^{\circ} \mathrm{C}\right)$. solution $4(0.03 \mathrm{M}$ glucose) (—), base electrolyte (- - ), sclution 9 (0.03M gluconic acid) (·-•-.). 


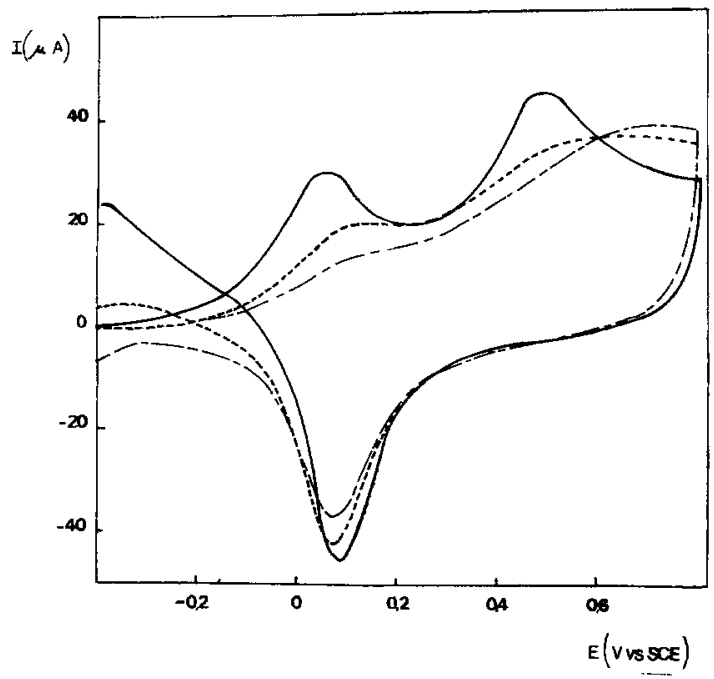

Fig. 5. Potentiodynamic $E / l$ profiles run at $30^{\circ} \mathrm{C}$ with solution 9 $\left(0.03 \mathrm{M}\right.$ glucose); $E_{3}=E_{\mathrm{ad}}=-0.4 \mathrm{~V}, \mathrm{t}_{\mathrm{ad}}=(\longrightarrow) 1 \mathrm{~min}$, $(--) 10 \mathrm{~min},(---) 60 \mathrm{~min}$.

trolytes used in the present work, however, the position of the complex current peak $\mathrm{V}$ becomes more cathodic; the largest shifts are observed for the concentrated buffered solutions.

The shape of the potentiodynamic $E / I$ profiles run with solution 2 between -0.6 and $1.0 \mathrm{~V}$ is appreciably different from that obtained with solution 1 . In the former case peak $V$ is strongly inhibited while the heights of peaks II and III increase (Fig. 6). Otherwise, the height of peak $\mathrm{V}$ decreases when the solution $\mathrm{pH}$ decreases. When the electrolyte is $\mathrm{K}_{2} \mathrm{SO}_{4}$-free (solutions 4 and 5) (Fig. 7) the $E / I$ profiles depend on the phosphate concentration and buffer capacity as in the case of solutions 1 and 2 (Fig. 6).

In the absence of phosphate anions (solution 6) the current hump IV turns into a current peak, while current peak $V$ appears apparently suppressed (Fig. 8). Conversely, current peak III becomes considerably higher than the rest of the anodic peaks. Similar results are obtained in neutral and acid electrolytes (solutions 7 and 8 ).

Runs made with solution 11 (Fig. 9) show the following changes in the potentiodynamic $E / I$ profile as the temperature increases: (i) a remarkable decrease of the charge related to the electrodesorption of the hydrogen adatoms; (ii) a strong increase in charge of current peaks II, III, and V; (iii) a relatively great increase in the height of peak II as compared to those of peak III; (iv) a net overvoltage decrease related to the oxygen evolution reaction (16), probably assisted by the presence of either glucose or any of its electro-oxi-

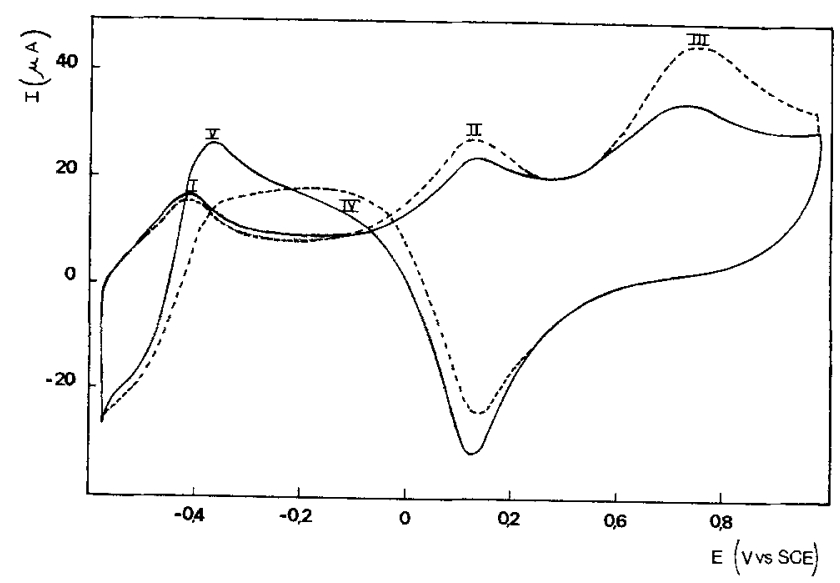

Fig. 6. Potentiodynamic $E / I$ profiles run at $30^{\circ} \mathrm{C}\left(E_{\mathrm{ad}}=-0.4 \mathrm{~V}\right.$, $t_{\text {ad }}=10 \mathrm{sec}$ ) with solution $1(0.1 \mathrm{M}$ glucose) (- $\longrightarrow$ and with

solution $2(0.1 \mathrm{M}$ alucose) (- $-\rightarrow$ )

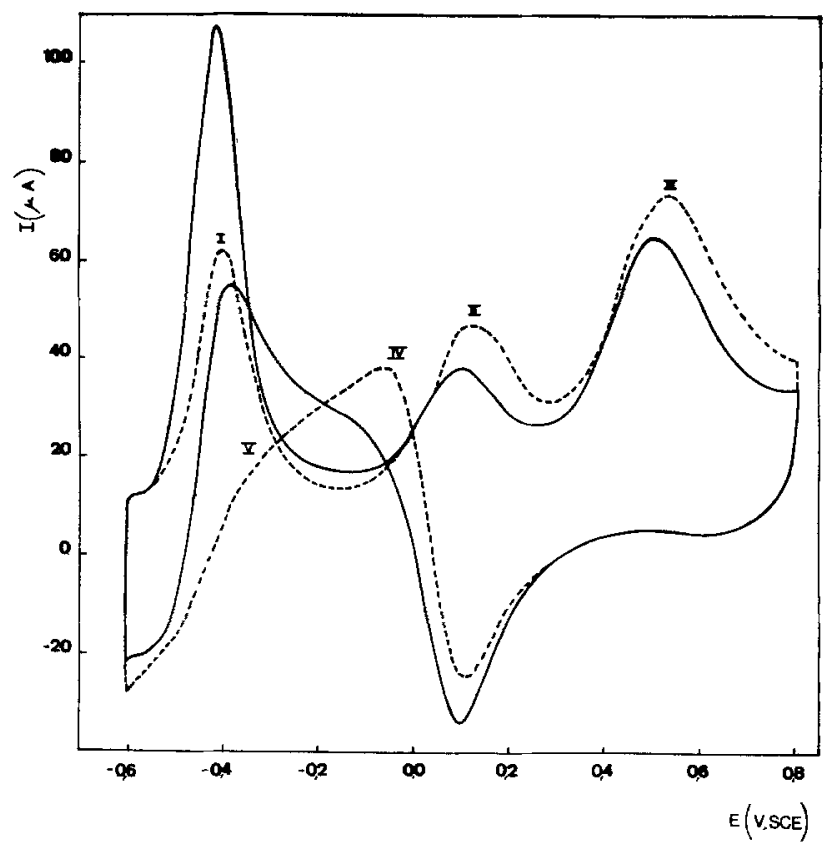

Fig. 7. Potentiodynamic $E / /$ profiles run at $30^{\circ} \mathrm{C}\left(E_{\mathrm{ad}}=-0.6 \mathrm{~V}\right.$, $\left.t_{\mathrm{ad}}=10 \mathrm{sec}\right)$ with solution $4(0.1 \mathrm{M}$ glucose) $(-\longrightarrow)$ and with solution 5 (0.1M glucose) (-- $)$.

dation products; $(v)$ a shift of the potential of the complex current peak $\mathrm{V}$ toward more positive values and, conversely, of the potentials of current peaks II and III toward more negative values; and (vi) practically no change in the oxygen electrodeposition charge. Voltammograms obtained in solution 11 saturated with carbon dioxide show that reduced carbon dioxide formed in the region of hydrogen adatoms are oxidized in the potential range of current peak II.

The TPS potentiodynamic $E / I$ profiles run after keeping the electrode at $-0.4 \mathrm{~V}$ show a strong inhibition for the electroadsorption and electrodesorption of hydrogen adatoms and a net increase of current peak II as $t_{\mathrm{ad}}$ increases. For solution 12 the $p H$ value decreases about one unit after carbon dioxide saturation. This probably causes a current increase in the potential region of the hydrogen adatoms as compared to the more concentrated buffered solution.

When carbon dioxide and glucose are simultaneously present current peak II is slightly greater than in the absence of glucose, while that of current peak $I$ is

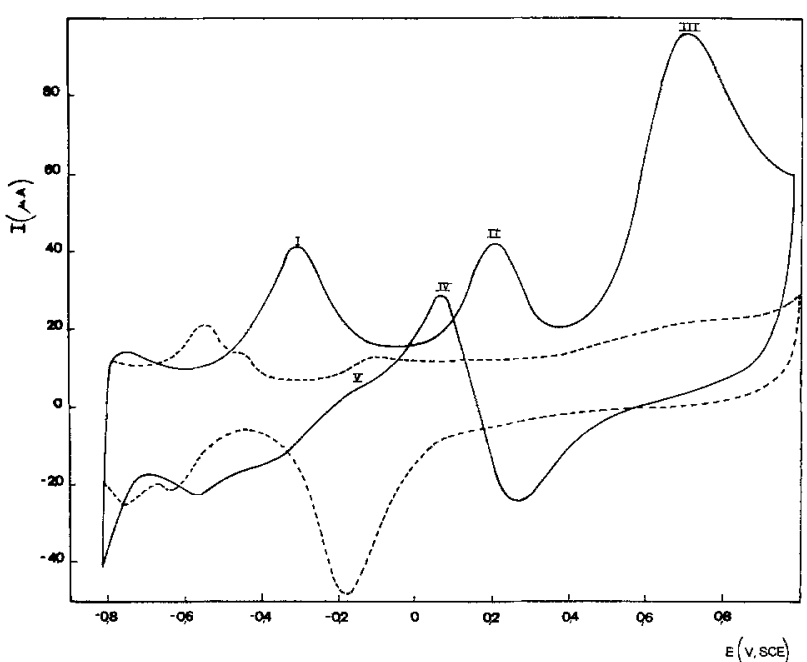

Fig. 8. Potentiodynamic $E / I$ profiles run at $30^{\circ} \mathrm{C}\left(E_{\mathrm{ad}}=-0.6 \mathrm{~V}\right.$, $\left.t_{\mathrm{ad}}=10 \mathrm{sec}\right)$ with solution $6(0.1 \mathrm{M}$ glucose $)(\longrightarrow$ and in base electrolyte (- - ). 


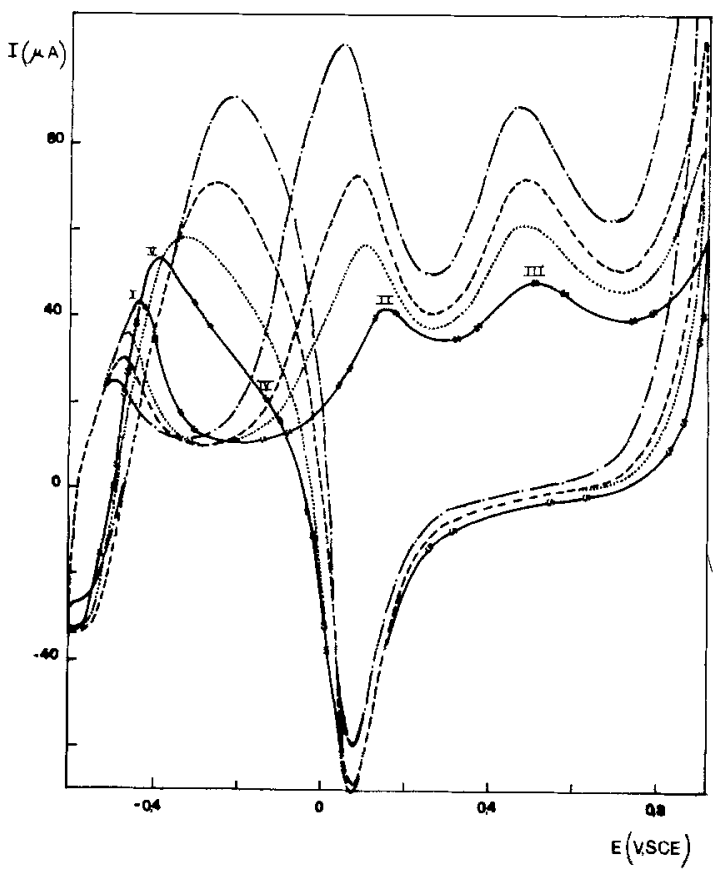

Fig. 9. Repetitive $E / /$ profiles run with solution $11(0.1 \mathrm{M}$ glucose) ot $\left.34^{\circ} \mathrm{C}(-2-), 44^{\circ} \mathrm{C}(\cdots \cdots), 54^{\circ} \mathrm{C}(--)\right)$, and $64^{\circ} \mathrm{C}$ (. - - ).

remarkably smaller than the one observed with solutions containing glucose (Fig. 10).

In agreement with previously reported results (13, 14), runs made after the addition of glucono-8-lactone to the electrolyte containing glucose show a strong inhibition of all the processes related to the electro-oxidation of glucose, especially those corresponding to peaks I and V. Glucono- $\delta$-lactone undergoes hydrolysis in the electrolyte yielding gluconic acid, the rate of this process being in the order of $10^{-3} \sec ^{-1}$ at $p H$ 7.5 and $20^{\circ} \mathrm{C}(17)$.

Experiments made with solutions 9 and 10 with added glucono- $\delta$-lactone exhibit two main potential ranges associated with the electro-oxidation processes. The former is located in the $0-0.3 \mathrm{~V}$ range and the second one stands beyond $0.4 \mathrm{~V}$ (Fig. 11). The $E / I$ profile changes gradually due to the hydrolysis of glu-

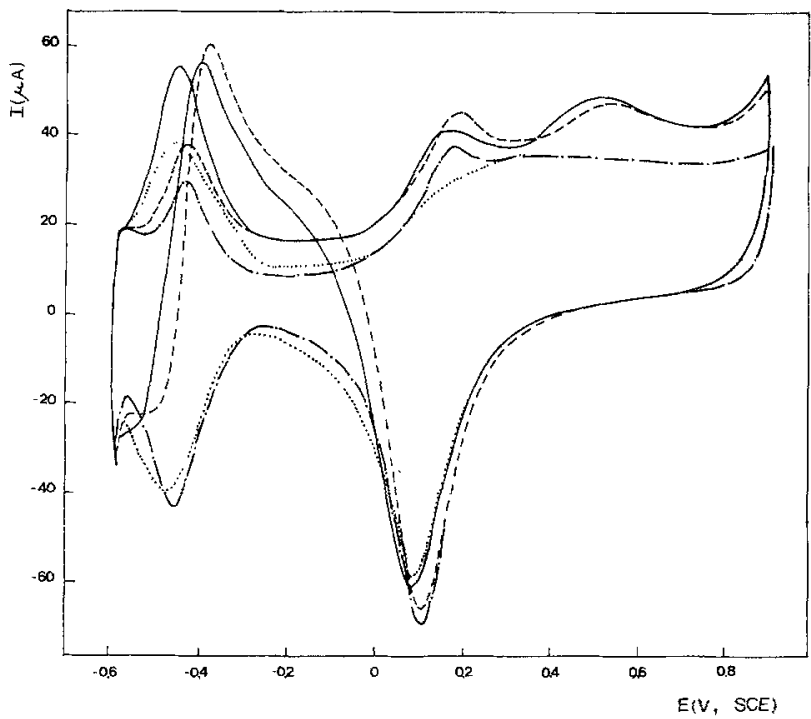

Fig. 10. Repetitive potentiodynamic $E / I$ profiles run at $30^{\circ} \mathrm{C}$ with (a) solution 11 ( $0.1 \mathrm{M}$ glucose) (- - ); (b) buffer electrolyte $(\cdots \cdots)$; (c) buffer electrolyte soturated with $\mathrm{CO}_{2}(\mathrm{pH}=6)$ $(-\cdot-)$; (d) solution $11\left(0.1 \mathrm{M}\right.$ glucose) saturated with $\mathrm{CO}_{2}(\mathrm{pH}$ = 6) $(---)$.

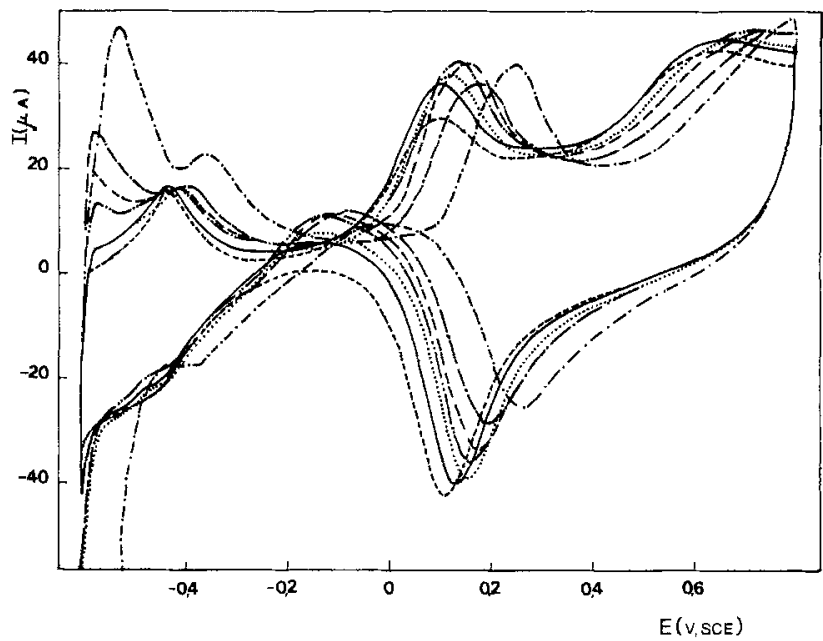

Fig. 11. Potentiodynamic E/I profiles corresponding to TPS run with solution $9\left(0.03 \mathrm{M}\right.$ glucose- $\delta$-lactone) at $37^{\circ} \mathrm{C}$ and different hydrolysis times, $t_{h}=2 \mathrm{~min}(--) ; 5 \mathrm{~min}(-(-) ; 10 \mathrm{~min}$ $(\cdots \cdot) ; 16 \min (-\cdots-) ; 20 \min (--) ; 30 \min (\cdot--\cdot) ; 50$ $\min (\cdot-\cdot)$.

cono- $\delta$-lactone as seen from the increase in height of the electro-oxidation peak recorded in the $0-0.3 \mathrm{~V}$ range, and simultaneously the decrease of the electrooxidation current observed at high anodic potentials. When the cathodic potential limit $E_{3}$ is increased the anodic current recorded in the former range decreases as it should be expected to if there is an interaction between the electro-oxidation process and the processes involving hydrogen adatoms. These changes of the voltamperogram suggest that the first anodic current peak is related to the electro-oxidation of gluconic acid. The location of the current peaks depends on both the $\mathrm{pH}$ and the anions present in solution. These experiments as well as those depicted in Fig. 4 revealed significant different electrochemical behavior of glucose and gluconic acid in the potential range of the electroadsorption/electrodesorption of hydrogen adatoms.

The voltammograms made with solutions containing arabinose and xylose (aldohexoses) are similar to those recorded with the solutions containing glucose. Otherwise, when glucose-1-phosphate dipotassium salt was added to the electrolyte very low oxidation currents were obtained (18). This indicates that the esterification of the hemiacetalic group makes a drastic change in the electro-oxidation process.

When fructose (ketohexose) is present in the electrolyte the $E / I$ profiles are similar to those obtained in the presence of gluconic acid. These results are useful in understanding with some detail the proper electrooxidation of glucose on platinum in the different electrolytes.

\section{Discussion}

According to various authors the electro-oxidation of glucose at $p H$ 7.4 on platinum electrodes gives rise to gluconic acid as the main product $(1,7,8)$. On the other hand, the second oxidation peak (II) was attributed to the oxidation of a common species, which was identified as "reduced $\mathrm{CO}_{2}$ " arising from both gluconic acid and glucose oxidation $(2,9-11,14)$. The present results show that the electrochemical oxidation of glucose on platinum strongly depends on the nature and concentration of ions in solution.

According to a previous work (2) the rate of formation of the oxidation intermediate indicates that the electro-oxidation of glucose occurs via the open chain or aldehyde form (2). However, the present results, in agreement with earlier reported data $(7,8)$, show that only those species with a hemiacetalic structure behave similarly to glucose. The $\mathrm{H}$ atom in the $\mathrm{C}-1$ atom is the most labile of the molecule. The decrease in $p \mathrm{~K}$ with increasing temperature $(19,20)$ corresponds to 
increasing acidity, that is, to a less binding energy between the proton and the glucose molecule. In alkaline solutions at about $40^{\circ} \mathrm{C}$ the increase in spectrophotometric absorption in the case of xylose solutions was attributed to the ring opening and the formation ô aldehyde forms (20).

It appears that the potentiodynamic electro-oxidation of glucose as well as the molecules involving a hemiacetalic group such as xylose and arabinose imply two main reaction stages, the first one being the electroadsorption of the molecule, which occurs at a relatively low potential $(7,8)$, and the second one to the electro-oxidation of the electroadsorbed species. The first stage is revealed by the current transient recorded under a constant potential step and the second stage come out from the characteristics of the potentiodynamic runs.

The charge involved in the potentiostatic transients can be associated with the formation of an adsorbed species at the electrode, according to an overall reaction such as

$$
\mathrm{G}+\mathrm{Pt} \rightleftarrows\left(\mathrm{R}_{\mathrm{i}}\right) \mathrm{Pt}+x \mathrm{H}^{+}+x e^{-}
$$

where $G$ and $\left(R_{i}\right)$ denote glucose and an adsorbed organic radical on the electrode, respectively. The electroadsorption of glucose molecule yielding different electroadsorbed species has been related to the high anodic current recorded in the $0.10-0.35 \mathrm{~V}$ (RHE) range (7). Reaction [1], however, corresponds to a complex process that depends on the hexose structure, on the solution composition, probably through the influence of the competitive adsorption of anions, and on the accessibility of the platinum surface, that is, on the hydrogen adatoms coverage. Therefore, the reactant entering reaction [1] should be strongly dependent on the ionic composition of the solution.

The adsorption of glucose on platinum in $0.5 \mathrm{M} \mathrm{H}_{2} \mathrm{SO}_{4}$ is maximum at $0.2 \mathrm{~V}$ ( $\mathrm{RHE}$ ), it diminishes when the potential moves in the positive direction due to oxidation of chemisorbed species and when the potential moves in the negative direction due to competition between adsorbed glucose and $\mathrm{H}$ adatoms (21). The nature of the chemisorbed species is apparently the same both in acid and alkaline electrolyte.

The second overall stage involved in the electrooxidation process can be formally represented by the reaction

$$
\left(\mathrm{R}_{\mathrm{i}}\right) \mathrm{Pt}+\mathrm{H}_{2} \mathrm{O} \rightleftarrows \text { Products }+y \mathrm{H}^{+}+y e^{-}
$$

The electro-oxidation of the chemisorbed species would require a number of electrons per adsorption site, which depends on the solution composition (21). This means the reaction is complex and the interpretation of its kinetics should start from the structural configuration of the reactants.

Glucose exhibits various possible structures in equilibrium

$$
\alpha-\mathrm{G} \rightleftarrows \gamma-\mathrm{G} \rightleftarrows \beta-\mathrm{G}
$$

where the $\alpha$ and $\beta$ species, which are more abundantly present in aqueous solutions, correspond to the cyclic hemiacetal forms and the $\gamma$-species denotes the free aldehyde form (22). Then, in principle, the anodic oxidation may start either from the $\alpha$ or the $\beta$-glucose, yielding in this case glucono- $\delta$-lactone as the first intermediate product, or from the aldehyde, which is directly oxidized to gluconic acid (8). However, as reported in the literature, in the potential range between 0.35 and $0.8 \mathrm{~V}$ (RHE), either gluconic acid (8) or carbon dioxide $(10)$ is a reaction product resulting from the electro-oxidation of glucose. In this potential region the reaction occurs on partially covered electrode, the adsorbate being probably a chemisorbed formed of lactone (8).

The balance of charges taking part both in the electroadsorption of glucose and in the electro-oxidation of the adsorbed species, illustrates the complex stoichiometry of the overall electro-oxidation. For this purpose, the charge involved in the O-electrodesorption process $\left(0.503 \mathrm{mC} / \mathrm{cm}^{2}\right)$ gives the maximum number of adsorption sites on the platinum electrode on the basis of 2 electrons per site. The roughness factor of the mechanically polished polycrystalline platinum electrode is equal to 1.31 , then the charge of the O-monolayer corresponds to $0.420 \mathrm{mC} / \mathrm{cm}^{2}$ and the actual charge expected for the $\mathrm{H}$-monolayer should be $0.276 \mathrm{mC} / \mathrm{cm}^{2}$. In the glucose-containing solutions the charge derived from the current transients under a potential step depends on both $E_{\text {ad }}$ and the composition of the electrolyte. The fact that in the range of the maximum adsorption potential the electroadsorption charge is larger than that corresponding to the $\mathrm{O}$-monolayer in the mixed electrolyte solutions, and the possibility that the electroadsorption charge may involve a number of molecules lower than that expected for a compact monolayer of a single electroadsorbed species, indicates that the number of electrons per glucose molecule involved in the overall electrooxidation process is greater than 2 . Nevertheless, it should be taken into account that during the electroadsorption stage some desorption of products may also be produced. When temperature is increased under a constant adsorption time, the decrease of peak I shows the greatest inhibition by adsorbed intermediates on the overall electro-oxidation process.

The fact that the number of electrons per glucose molecule in the electroadsorption process is greater than 2 does not preclude that gluconic acid become the main reaction intermediate which can be detected at different potentials during the potentiodynamic $E / I$ display (7-9). As a matter of fact, through the present results it is reasonable to consider reaction [1] as a complex reaction where different $R_{i}$ species are formed, the value of $x$ in reaction [1] depending then on the way the reaction proceeds, as well as solution composition and temperature. Furthermore, within the potential range of current peak I there are still additional kinetics complications. One of them concerns the possible chemical reaction between the $R_{\mathrm{i}}$-species and the $\mathrm{H}$-adatoms, which are simultaneously present on the platinum surface. Such a reaction accounts for the decrease of the peak I current value corresponding to glucose electroadsorption when $t_{\mathrm{ad}}$ increases at a constant $E_{\text {ad }}$ (Fig. 2) and when the cathodic switching potential of the successive triangular potential sweeps cover the hydrogen adatom potential range. Another complication is related to the possible presence of carbon dioxide appearing in solution as one of the reaction products. Carbon dioxide interacts with the H-adatoms yielding the reduced carbon dioxide species, which is electro-oxidized in the potential range where peak II is observed. The results obtained with solutions containing carbon dioxide (Fig. 10) confirm those recently published (10). On the other hand, gluconic acid is oxidized within the same potential range of glucose electro-oxidation.

A further complication to the reaction, particularly in phosphate-containing solution, comes from the effect of anion adsorption. The adsorbability of phosphoric acid ionic species on various metals, including platinum, varies greatly with the solution $p H$, with increasing temperature, and with increasing electrochemical polarization. The maximum adsorption effect is obtained at $\mathrm{pH} 7.7$, (23) although under comparable conditions the various species involved in the polybasic phosphoric acid equilibria may exhibit different adsorbabilities. The degree of dissolution of phosphoric acid at $25^{\circ} \mathrm{C}$ is determined by the following $p H$ values

\subsection{3} 7.19

$\mathrm{H}_{3} \mathrm{PO}_{4} \rightleftarrows \mathrm{H}^{+}+\mathrm{H}_{2} \mathrm{PO}_{4}-\stackrel{.19}{\rightleftarrows} \mathrm{H}^{+}+\mathrm{HPO}_{4}^{2-}$

$$
\stackrel{12.03}{\rightleftarrows} \mathrm{H}^{+}+\mathrm{PO}_{4}^{3-}
$$


The $\mathrm{HPO}_{4}{ }^{2-}$ ion is probably adsorbed at the metal/ electrolyte interface through the formation of an oxygen-metal adsorptive bond (24). The adsorption minimum of phosphate ion should correspond to the potential of zero charge of the metal (24). Therefore, when considering the mechanism of electrochemical oxidation of glucose at platinum a competitive adsorption between glucose and anions for the adsorption sites on the metal should be established.

On the basis of this discussion, a general electrooxidation mechanism of glucose on platinum can be presented, which in a particular way may include those already proposed by Heitbaum and Ernst and by Giner et al. $(7,8,10)$. As the total number of electrons entering the overall reaction lies between 2 and 24 , the following limiting total reactions can be presented

and

$$
\mathrm{G}+\mathrm{H}_{2} \mathrm{O}=\mathrm{GA}+2 e^{-}+2 \mathrm{H}^{+}
$$

$$
\mathrm{G}+6 \mathrm{H}_{2} \mathrm{O}=6 \mathrm{CO}_{2}+24 \mathrm{H}^{+}+24 \mathrm{e}^{-}
$$

where $\mathbf{G}=$ glucose and $\mathbf{G A}=$ gluconic acid.

The reaction pathway consists of the following stages.

Stage I $[\mathrm{Pt} / \mathrm{Pt}(\mathrm{H})$ region]. (i) The electroadsorption processes given by the following steps

$$
\begin{aligned}
(x+m) \mathrm{Pt}\left(\mathrm{X}^{-}\right) & +\alpha-\mathrm{G} \rightleftarrows m \mathrm{X}^{-} \\
& +m \mathrm{Pt}(\mathrm{H})+\mathrm{Pt}_{x}\left(\mathrm{R}_{\mathrm{i}}\right) \rightleftarrows m \mathrm{H}^{+} \\
& +m \mathrm{Pt}\left(\mathrm{X}^{-}\right)+\mathrm{Pt}_{x}\left(\mathrm{R}_{\mathrm{i}}\right)+m e^{-} \\
(x+m) \mathrm{Pt}\left(\mathrm{X}^{-}\right) & +\gamma-\mathrm{G} \rightleftarrows m \mathrm{X}^{-} \\
& +m \mathrm{Pt}(\mathrm{H})+\mathrm{Pt}_{x^{\prime}}\left(\mathrm{R}_{\mathrm{i}}\right) \rightleftarrows m \mathrm{H}^{+} \\
& +m \mathrm{Pt}\left(\mathrm{X}^{-}\right)+\mathrm{Pt}_{x}\left(\mathrm{R}_{\mathrm{i}}\right)+m e^{-} \\
(x+m) \mathrm{Pt}\left(\mathrm{X}^{-}\right) & +\beta-\mathrm{G} \rightleftarrows m \mathrm{X}^{-} \\
& +m \mathrm{Pt}\left(\mathrm{H}^{-}\right)+\mathrm{Pt}_{x^{\prime}}\left(\mathbf{R}_{\mathrm{i}}\right) \rightleftarrows m \mathrm{H}^{+} \\
& +m \mathrm{Pt}\left(\mathrm{X}^{-}\right)+\mathrm{Pt}_{x}\left(\mathbf{R}_{\mathrm{i}}\right)+m e^{-}
\end{aligned}
$$

and

$$
\begin{aligned}
(x+m) \mathrm{Pt}\left(\mathrm{H}_{2} \mathrm{O}\right) & +\alpha-\mathrm{G} \rightleftarrows \mathrm{mH}_{2} \mathrm{O} \\
& +\mathrm{Pt}_{x}\left(\mathrm{R}_{\mathrm{i}}\right)+m \mathrm{Pt}(\mathrm{H}) \rightleftarrows m \mathrm{H}^{+} \\
& +m \mathrm{Pt}\left(\mathrm{H}_{2} \mathrm{O}\right)+\mathrm{Pt}_{x}\left(\mathrm{R}_{\mathrm{i}}\right)+m e^{-} \\
(x+m) \mathrm{Pt}\left(\mathrm{H}_{2} \mathrm{O}\right) & +\gamma-\mathrm{G} \rightleftarrows m \mathrm{H}_{2} \mathrm{O} \\
& +\mathrm{Pt}_{x}\left(\mathrm{R}_{\mathrm{i}}\right)+m \mathrm{Pt}(\mathrm{H}) \rightleftarrows m \mathrm{H}^{+} \\
1 & +m \mathrm{Pt}\left(\mathrm{H}_{2} \mathrm{O}\right)+\mathrm{Pt}_{x}\left(\mathrm{R}_{\mathrm{i}}\right)+m e^{-}
\end{aligned}
$$

$(x+m) \mathrm{Pt}\left(\mathrm{H}_{2} \mathrm{O}\right)+\beta-\mathrm{G} \rightleftarrows m \mathrm{H}_{2} \mathrm{O}$

$$
\begin{aligned}
& +\mathrm{Pt}_{x}\left(\mathrm{R}_{\mathrm{i}}\right)+m \mathrm{Pt}(\mathrm{H}) \rightleftarrows m \mathrm{H}^{+} \\
& +m \mathrm{Pt}\left(\mathrm{H}_{2} \mathrm{O}\right)+\mathrm{Pt}_{x}\left(\mathbf{R}_{\mathrm{i}}\right)+m e^{-}
\end{aligned}
$$

the parentheses denote adsorbed species, either anions $\left(X^{-}\right)$or radicals $\left(R_{i}\right)$. In concentrated buffered solutions, $\alpha-G$ and $\beta-G$ are the main reactive forms. However, depending on the electrolyte composition and temperatures, $\gamma-G$ may become the principal reactant. The dehydrogenation processes ([6a]-[6c]) and $([7 a]-[7 c])$ may be accompanied by a bond breaking in the organic molecule, a fact commonly observed in many electro-oxidation reactions with organic molecules.

(ii) The possible chemical reactions can be formally written as follows

$$
\mathrm{H}_{2} \mathrm{O}+\mathrm{Pt}_{x}\left(\mathrm{R}_{\mathrm{i}}\right) \rightleftarrows \mathrm{R}_{\mathrm{i}}+x \mathrm{Pt}\left(\mathrm{H}_{2} \mathrm{O}\right)
$$

This type of reaction has been considered in the reaction scheme advanced by Heitbaum et al. (7).
Gluconolactone as a reaction intermediate may be represented by the $\mathrm{Ri}$-species with $n=2$. In this case the adsorption equilibrium of reaction (8), given in terms of gluconolactone

$$
\mathrm{Pt}_{x}(\mathrm{GL})+x \mathrm{H}_{2} \mathrm{O} \rightleftarrows \mathrm{GL}+x \mathrm{Pt}\left(\mathrm{H}_{2} \mathrm{O}\right)
$$

would explain the presence of the latter in solution when either neutral or acid electrolytes are used. The $\mathrm{R}_{\mathrm{i}}$-species undergoes hydrolysis yielding the acid products

$$
\mathrm{R}_{\mathrm{i}}+\mathrm{H}_{2} \mathrm{O} \rightleftarrows \mathrm{R}_{\mathrm{i}-1} \mathrm{COOH}
$$

Reaction [9] for gluconolactone (GL) is

$$
\begin{gathered}
\mathrm{GL}+\mathrm{H}_{2} \mathrm{O} \rightleftarrows \mathrm{GA} \\
\mathrm{GA} \rightleftarrows \text { gluconate }+\mathrm{H}^{+}
\end{gathered}
$$

However, in considering the possible chemical reactions the following inhibition reaction cannot be disregarded

$$
(x-1) \mathrm{Pt}+\mathrm{R}_{\mathrm{I}}+\mathrm{Pt}(\mathrm{H}) \rightleftarrows \mathrm{Pt}_{x}\left(\mathrm{R}_{\mathrm{i}} \mathrm{H}\right)
$$

where the desorption step may, under certain conditions, become rate controlling. The desorption of $R_{i}$ or $\mathrm{R}_{\mathrm{i}} \mathrm{H}$ could be probably accelerated in the presence of phosphate anions. The latter, however, can also interfere with the formation of the $\left(R_{i} H\right) P t$ species. In this way, the activation of the electro-oxidation reaction by phosphate ions in the hydrogen adatom potential range particularly when concentrated buffered solutions are used can be explained

Stage II [Pt/Pt $(\mathrm{OH})$ region]. Electroadsorption and electro-oxidation processes.

The final fate of any $R_{1}$ species is $\mathrm{CO}_{2}$, which is produced according to

$$
\mathrm{Pt}_{x}\left(\mathrm{R}_{\mathrm{i}}\right)+x \mathrm{H}_{2} \mathrm{O} \rightarrow \mathrm{CO}_{2}+n \mathrm{H}^{+}+n e^{-}+x \mathrm{Pt}\left(\mathrm{H}_{2} \mathrm{O}\right)
$$

where $m+n=24$ electrons per glucose molecule. Nevertheless, the electro-oxidation of glucose is not a direct electrochemical process, but it should occur through the formation of a variety of intermediate species. In the potential range of reaction [12] at least two steps should be distinguished on the free platinum surface, namely the electroformation of $(\mathrm{OH})$ species

$$
\mathrm{Pt}+\mathrm{H}_{2} \mathrm{O} \rightleftarrows \mathrm{Pt}(\mathrm{OH})+\mathrm{H}^{+}+e^{-}
$$

and the electro-oxidation process, which can be formally represented as the overall reaction

$\mathrm{H}_{2} \mathrm{O}+\mathrm{Pt}_{x}\left(\mathrm{R}_{\mathrm{i}}\right) \rightarrow \mathrm{CO}_{2}+n \mathrm{H}^{+}+n e^{-}+x \mathrm{Pt}(\mathrm{OH})$

Reaction [13] is already well known in the electroadsorption of oxygen species on platinum $(25,26)$ and reaction [14] is a process commonly observed in fuel cells using organic substances. The influence of anions in the threshold potential for the oxygen electrosorption is already known and applies to reaction [13] and the following stages yielding $\mathrm{Pt}(\mathrm{O})$ adsorbed species.

The above-mentioned reaction pathway takes into account the influence of the anion adsorption and the adsorption of intermediates as well as the reaction products derived from carbon dioxide or any other reduced species with the adsorbed hydrogen adatoms. It also means that the main reactant may change on the solution $\mathrm{pH}$ according to reactions [6]-[14] and finally, that under potentiodynamic conditions the contribution of each stage involved in the overall reaction pattern should also depend on the potential sweep rate and switching potentials. This makes questionable the extension of any particular reaction mechanism derived under nonstationary conditions to those stationary runs that represent the actual useful conditions of any electrochemical device operating on the glucose electro-oxidation reaction. 


\section{Acknowledgment}

INIFTA is sponsored by the Consejo Nacional de Investigaciones Científicas y Técnicas, the Universidad Nacional de La Plata, and the Comisión de Investigaciones Científicas (Provincia de Buénos Aires).

Manuscript submitted Nov. 9, 1981; revised manuscript received March 15, 1982.

Any discussion of this paper will appear in a Discussion Section to be published in the June 1983 JournaL. All discussions for the June 1983 Discussion Section should be submitted by Feb. 1, 1983.

\section{REFERENCES}

1. M. L. B. Rao and R. F. Drake, This Journal, 116, 334 (1969)

2. J. Giner and P. Malachesky, in "Proceedings of the Artificial Heart Program Conference," p. 839, Washington, DC (1969).

3. S. Yao, A. Appleby, A. Geisel, H. Cash, and S. Wolfson, Nature, 224, 921 (1969).

4. E. Weidlich, G. Richter, F. von Sturn, and J. R. Rao, Biomat. Med. Dev. Art. Org., 4, 277 (1976).

5. J. R. Rao, G. Richter, F. von Sturm, and E. Weidlich, Bioelectrochem. Bioenerg., 3, 139 (1976).

6. G. Slama and S. Bessman, J. Ann. Diabetol., 297 (1976).

7. S. Ernst, J. Heibtaum, and C. Hamann, J. Electroanal. Chem. Interfacial Electrochem., 100, 173 (1979).

8. S. Ernst, J. Heibtaum, and C. Hamann, Ber. Bunsenges. Phys. Chem, 84, 50 (1980).
9. K. Ito, S. Ikeda, H. Yamaguchi, K. Ito, and T. Kondo, Denki Kagaku Oyoki, 43, 141 (1978).

10. H. Lerner, J. Giner, J. Soeldner, and C. Colton, This Journal, 126, 237 (1979).

11. L. Marinsic, J. Soeldner, C. Colton, J. Giner, and S. Morris, ibid., 126, 43 (1979).

12. D. Gough and J. Leypoldt, ibid., 127, 1278 (1980).

13. E. M. Skou, Ext. Abst. 279, 27th ISE Meeting, Zurich (1976).

14. E. M. Skou, Ext. Abst. 668, 29th ISE Meeting, Budapest (1978)

15. E. M. Skou, Electrochim. Acta, 22, 313 (1977).

16. M. R. John, A. Furgala, and A. Sammells, This Journal, 128, 1175 (1981).

17. E. M. Skou, Thesis, Lyngby, Denmark (1974).

18. M. F. L. de Mele, H. A. Videla, and A. J. Arvía, To be submitted.

19. P. Ballinger and F. A. Long, J. Am. Chem. Soc., 82, $795(1960)$.

20. J. J. Christensen, J. Howard Rytting, and R. M. Izett, J. Chem. Soc. London B, 1646 (1970).

21. N. N. Nikolaeva, O. A. Khazova, and Yu. B. Vasil'ev, Elektrokhimiya, 16, 1227 (1980).

22. A. W. Fonds and J. M. Los, J. Electroanal. Chem. Interfacial Electrochem., 36, 479 (1972).

23. M. N. Barikov, R. S. Vakhidov, and W. V. Joslovich, Elektrokhimiya 16, 1012 (1980)

24. R. S. Vakhidov and M. N. Barikov, ibid., 11, 282 (1975).

25. A. Kozlowska, B. E. Conway, and W. B. A. Sharp, J. Electroanal. Chem. Interfacial Electrochem., $\mathbf{4 3}, 9$ (1973).

26. M. E. Folquer, J. O. Zerbino, N. R. de Tacconi, and A. J. Arvia, This Journal, 126, 593 (1979).

\title{
Lithium Closoborane Electrolytes
}

\section{Preparation and Characterization}

\author{
Jack W. Johnson and John F. Brody \\ Exxon Research and Engineering, Corporate Research, Linden, New Jersey 07036
}

\section{ABSTRACT}

The lithium closoborane salts $\mathrm{Li}_{2} \mathrm{~B}_{10} \mathrm{Cl}_{10}$ and $\mathrm{Li}_{2} \mathrm{~B}_{12} \mathrm{Cl}_{12}$ were prepared from decaborane, purified, and dissolved in 1,2-dimethoxyethane (DME)/1,3-dioxolane mixtures. The solubility behavior is complex, as the salts are insoluble in either solvent alone, and concentrated solutions separate into two liquid phases upon dilution. Electrolyte resistivity measurements as a function of temperature and concentration are reported. These electrolytes have resistivities of approximately $150 \Omega \mathrm{cm}$ at room temperature and are quite stable, making them attractive candidates for applications in lithium cells. ponent in the development of high energy density secondary batteries that operate at or near ambient temperature. In order for a battery system to be capable of extended cycle life, the electrolyte salt and the nonaqueous solvent employed must exhibit extraordinary chemical stability to both reduction by $\mathrm{Li}$ metal and oxidation by the cathode material, as well as sufficient conductivity to allow cell operation at the desired rates. An ideal electrolyte salt would be composed of $\mathrm{Li}$ cations and a large inert anion that could be approximately viewed as a hard sphere. The anion should be large and have its negative charge delocalized in order to enhance solubility. Inertness to both electrochemical and chemical side-reactions is another necessary requirement. We have investigated the Li closoborane salts in DME/dioxolane solution as electrolytes in $\mathrm{Li}-\mathrm{TiS}_{2}$ cells operated at ambient (1) and intermediate (2) temperatures. In this paper, we will describe in detail the preparation, purification, and properties of these electrolytes (3).

Closoborane anions are a family of inorganic species that approximate the hard sphere model (4). These
Nonaqueous lithium electrolytes are a crucial com-

anions, examples shown in Fig. 1, are composed of a cluster of ten or twelve boron atoms, each bound to a terminal hydrogen or halogen atom. The resulting shape is roughly spherical and the dinegative charge is evenly distributed. Hence, lithium salts of such anions should exhibit good electrolyte properties, as the closoborane anions will have little affinity for the lith-
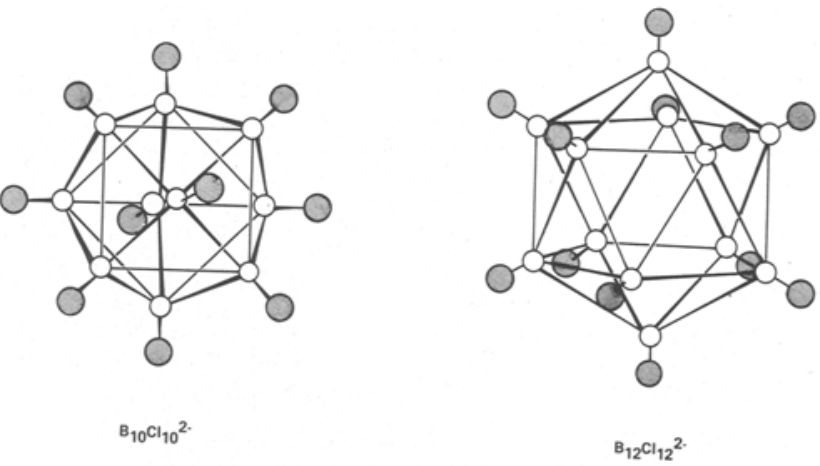

Fig. 1. Structures of the closoborane anions 